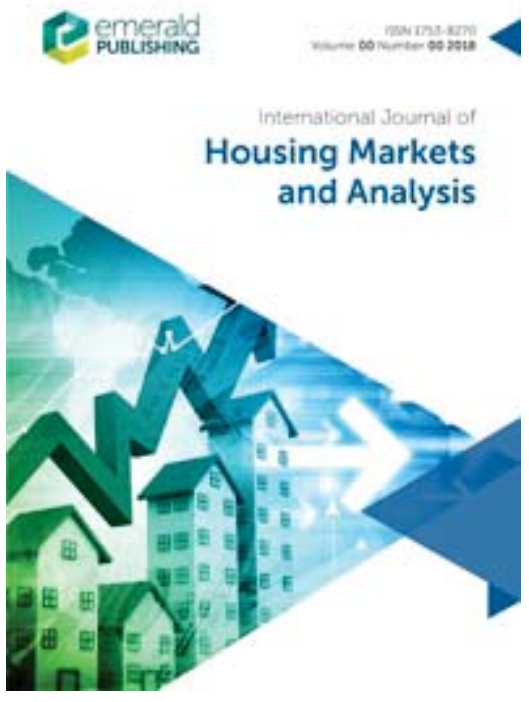

\title{
Contributions of path-dependency and social capital drivers to housing tenure transitions in Britain
}

\begin{tabular}{|r|l|}
\hline Journal: & International J ournal of Housing Markets and Analysis \\
\hline Manuscript ID & IJHMA-10-2018-0078.R1 \\
\hline Manuscript Type: & Research Paper \\
\hline Keywords: & $\begin{array}{l}\text { housing tenure, social capital, path-dependence, parental housing, home } \\
\text { ownership, private renting }\end{array}$ \\
\hline \multicolumn{2}{|l}{} \\
\hline
\end{tabular}

\section{SCHOLARONE Manuscripts}




\section{Abstract}

\section{Purpose}

This paper investigates the contributions of path-dependency and some contextual social capital drivers to housing tenure transitions in Britain. Different situations have continued to shape young adults' housing tenure decisions. However, very little research has been done to investigate the impact of some social capital drivers, such as neighbourhood integration and strength of parental intimacy, on housing tenure decisions in Britain.

\section{Methodology}

The study is carried out by tracking a sample of young adults in the British Household Panel Survey from 1991 to 2015 until they make tenure transition. Multinomial fixed-effects logistic regression of time to tenure transition was useful for the models, incorporating established economic and demographic drivers and with the inclusion of contextual social capital variables.

\section{Findings}

The inclusion of the number of years of parental home ownership experience tends to improve on previous path-dependency indicators of tenure transition. With additional years of parental home ownership experience, British young adults are more likely to remain or return to parental housing. Also, individuals that exchange better with their neighbours are less likely to switch tenure. On the other hand, regularity of contact with parents showed a positive relationship with home ownership or parental housing transitions.

\section{Originality/value}

To the best of the author's knowledge, no study has explored the impact of the duration of socialisation in parental housing, and also the impact of some other social capital drivers, such as neighbourhood integration and strength of parental intimacy, on housing tenure decisions among young adults. Hence, it is believed that the findings will further assist policymakers in understanding the dimensions and drivers of tenure shifts. 


\section{Introduction}

Housing is one of the most debated issues in any economy, particularly in advanced economies. It is seen to be an influential factor in people's social and family life. The housing market in the UK has had different price cycles in the past decades and this had led to issues related to tenure decisions (i.e. whether to buy or to rent, depending on the circumstance), wealth and housing imbalance among generations. Housing tenure transition models have, over time, been important for investigating the influences of housing tenure decisions (See Henderson and Ioannides (1983); Bourassa (1995); Di Salvo and Ermisch (1997)). More recent trends and timing of tenure transitions show some well-established drivers contributing to housing tenure decision making (e.g. in Andrew (2012); Baddeley (2011); Ben-Shahar (2007)). To the best of the author's knowledge, no study has explored the impact of the duration of socialisation in parental housing on housing tenure decision among young adults in Britain. Furthermore, no study has gone further to investigate the impact of some social capital drivers, such as neighbourhood integration and strength of parental intimacy, on housing tenure decisions in Britain. Hence, as changes keep occurring in decision making over time, continued testing of more potential influences of the transitions is, therefore, necessary to inform policy decisions.

This paper, therefore, starts with a literature review on housing tenure decisions in Britain and the justification for the investigation. A conceptual framework follows and afterwards, the model specification for the analysis is laid out and an innovative approach is taken by tracing the applicable panel survey sample respondents from 1991 to 2014/2015 inclusive. Social capital drivers are exclusively included in the models alongside other established drivers in multinomial logistic regression models. The paper ends with concluding discussions.

\section{Literature Review}

\section{Influences of housing tenure decisions in Britain}

Explorations of the influences of housing tenure decisions among young adults have mostly taken an econometric approach, with a focus widely on economic and demographic influences on tenure decisions. Housing tenure decisions for individuals and households have been largely seen in terms of the neoclassical point of view. That is, consumers can maximise their satisfaction by making their choices rationally. Other views have also emerged in 
literature, such as state control, spatial or geographical approach and the growing sociological views (Clapham, 2005). Laszek (2013) also demonstrated the complexity inherent in housing decisions as part of consumer behaviour. Nevertheless, economic influences have been the major contributor to decision-making over the years. Among the prominent ones are consumer incomes (Andrew and Meen, 2003; Robst et al., 1999; Gathergood, 2011; Di Salvo and Ermisch, 1997); credit and affordability requirements (Quercia et al., 2003; Andrew, 2012). On the other hand, findings have also indicated demographic influences such as marriage, gender, race, norms, status, age and family as factors affecting tenure decisions (see Baddeley, 2011; Drew, 2014; Fu, 2014). In recent literature, a different dimension to the drivers of housing tenure decision has emerged. Socio-psychological drivers are being considered, although they have not been examined in depth from the econometric context. Among these are beliefs and expectations (Ben-Shahar, 2007; Drew, 2014); motivations (Reid, 2013); spending and saving behaviour (Ab Majid et al., 2014).

In recent times, the reasons for the expansion of the Private Rented Sector (PRS) have also been a subject of argument. Although previous studies have highlighted wide-ranging causes for this ${ }^{1}$. The established drivers have not fully explained the changes taking place in young people's decision making in Britain. Hence, the suggestion is that credible sociopsychological influences on housing decisions for young adults in Britain need to be investigated further. This is particularly driven by the growing 'preference' for the PRS as against pursuing home ownership, while some others are determined to get on the housing ladder regardless of unfavourable conditions of accessibility. Clapham (2005) also argued that housing research still lacks a deeper understanding of subjectivity in tenure decisionmaking.

Certainly, putting past events into measurable perspective in an econometric context has been very helpful in recent housing tenure transition models. However, the subjective norm in the form of standards that may have been set by connected individuals or groups, and consistent with subjective enthusiasm to follow suit is also very important. An example is the pursuance of a specific housing tenure based on standards set by the socioeconomic group or family members. For instance, could it be that young people have integrated so well into their past and present neighbourhoods and as a result, are thereby influenced into their recent housing decisions? Or perhaps some parental influence of some sort? On one hand, socialisation has

\footnotetext{
${ }^{1}$ For a good summary, see Heath (2008).
} 
been seen as an important driver of such decision making in recent studies. As an example, young people's housing outcomes are connected to their parents' housing background (See Coulter (2016) and Wagner (2014)). The number of years lived in parental housing may further improve the explanations surrounding path-dependency for young adults' housing tenure decisions and their possibility to transition to another tenure. On the other hand, social capital drivers may be influential in housing decisions. In order to probe the influences of social capital drivers further, this paper therefore specifically investigates the contributions of the number of years lived in parental home ownership, intimacy with parents and neighbourhood integration to housing tenure decisions among British young adults.

\section{Event occurrence, path-dependence and social capital in housing tenure decisions}

Exploring the events that contribute to changes between major tenures is prominent in housing tenure research. Housing tenure decisions can often times be diverse and considerably reliant on past events, as illustrated in Ermisch and Di Salvo (1996) and Clapham (2005). Events which could influence movements across housing tenures are conceptualised in Clapham et al (2014). The study appears to expand on the five pathways identified in Ford et al (2002) by identifying nine different paths to tenure decision, mainly shaped by unexpected events, significant restraints and inadequate means available. These movements are not necessarily a perceived upward only trajectory as some recent studies portray (see Koppe, 2016; Druta and Ronald, 2017; Ronald and Lennartz, 2018) but also includes different other movements which could be backward (see Arundel and Lennartz, 2018) or relatively unchanged circumstance. This study, however, identifies four major housing tenures for young people in Britain and consequently, twelve possible movements across tenures are achieved (see table 1).

Socialisation is another concept on which path-dependency in tenure is strongly based (Lersch and Luijkx, 2015; Lux et al, 2018; Coulter, 2016). These studies found direct effects of social histories or parental influence on eventual housing outcomes of young people. What they, however, did not provide is the duration of socialisation that eventually shapes young people's tenure decisions, especially towards owner occupation. Aside from this, social capital proves to be the resources entrenched in social networks (Lin, 2017) which, in this study, emphasizes the importance of connections and groups an individual belongs. These 
connections and associations, in the form of neighbourhood integration and family ties, may further influence their lifetime decisions ${ }^{2}$.

In housing tenure outcomes, young people are likely to be faced with the possibility of controlling their transition to independence; the issues that shape their housing accessibility; and the existence of direct relations to influence their housing decisions (Ford et al., 2002). Influence of direct family relations has become an established driver of tenure decision. This study sees the influence as part of social capital drivers of tenure transitions. The background knowledge of social capital divides the concept into two (Brady, 2015). These are strong ties relating to individual's direct family members or friends on one hand, and weak ties relating to colleagues or members of social or economic groups in which the individual is involved. Another popular division of social capital in the literature is to see the concept as consisting of three separate dimensions, i.e. bonding, linking and bridging (Brook, 2005). "Bonding" is referred to as the association between close relations and friends; "linking" refers to the connections with associations and organisations; while "bridging" is the association between associates and colleagues. These associations and connections reveal how they influence eventual outcomes of individuals. Some studies, such as Leviten-Reid and Matthew (2017) and Ziersch and Arthurson (2007) have found connections between social capital and housing tenure outcomes.

In this study, two "bonding" factors (i.e. conversations with neighbours and neighbourhood likeness) and one "linking" factor (i.e. activeness in local organisations) have been adopted from Leviten-Reid and Matthew (2017). Networks of social capital could be helpful in getting information and guidance, or they may give room for key opportunities, thereby influencing a wide range of personal outcomes (Brook, 2005). These tend to trigger conversations and trust (Mandell, 2010), thereby assisting individual's important decision making process. Bonding factors, especially, could enhance integration in the environment, thus making the individual feel accepted in the area or delay transitions. "Frequency of contact with parents" also represents an important network which could help guide or assist individuals into important decisions, as is the case of housing tenure. Unlike previous studies, this study specifically focuses on the connections between social capital and movement

\footnotetext{
2 Socialisation and social capital are two concepts that are closely related. Socialisation is a much broader concept, emphasizing the process of learning to follow others' norms and ideologies (e.g., as in the case of parental home ownership and home ownership decisions). Social capital, on the other hand, may originate from socialisation, but further emphasizes the networks of relationships among individuals in certain groups or ties (See Lin, 2017).
} 
across tenures for young people. Causality is often debated in relationships like these. For example, there could be spillover effects (McCabe, 2012) because of the generation of social capital from certain tenure types. However, due to the connections that exist between the measurements, the estimation process takes care of possible omitted variables bias ${ }^{3}$. Hence, rather than focusing on very limited tenure trajectory as they connect with social capital, this study explores the influence of possible social capital drivers in a wider tenure movement patterns for young adults in Britain.

To summarize, this study chooses a longitudinal approach using multinomial logistic regression, described in the next section, to examine the contributions of some contextual path-dependency and social capital variables to tenure transitions in Britain.

\section{Data and Model Specification}

The data used in this study is the first twenty-four waves of the British Household Panel Survey (BHPS). The BHPS is a socioeconomic longitudinal study of households in the UK (University of Essex. Institute for Social and Economic Research, 2010). The sample collection refers to the years 1991 to 2008/2009 (18 waves) respondents and 2009 to 2014/15. The BHPS collection originally started in 1991 with up to 5,500 households. The sample also contains individuals aged 18-34 and who are in any of four distinct categories of the tenures such as owner-occupation ${ }^{4}$, private renting ${ }^{5}$, social renting ${ }^{6}$ and 'living with parents' ${ }^{7}$. This provides a platform for testing the drivers of transitions into different housing tenures or remaining in the same tenure. Furthermore, the sample is restricted to individuals who are present in at least three consecutive waves of sample collection (Ermisch and Di Salvo, 1996, Curran et al., 2010). By following this approach, it is impossible to avoid gaps in the sample but could secure a very good longitudinal data for every individual without losing much information in our 24-year survey.

\footnotetext{
${ }^{3}$ Unobserved heterogeneity has been considered and dealt with using the fixed-effects regression technique (See Gormley and Matsa, 2013).

${ }^{4}$ This includes heads of households (or partners) and indicated to either own their house outrightly or with mortgage.

${ }^{5}$ This includes heads of households (or partners) and indicated that they live in the non-socially rented apartments.

${ }^{6}$ This includes heads of households (or partners) and indicated that they live in either local authority or housing association housing.

${ }^{7}$ These are individuals excluded in the homeownership, private renting and social renting because they are yet to form households. They also include those in full-time education.
} 
The sample represents individuals who were interviewed at or before age 34 and transitioned or remained in the same tenure in the years of the survey. This means that each respondent grows older every year until the 2014/15 analysis endpoint. The selection resulted in 9594 British individuals that were interviewed throughout the survey period. The mean age of participants when they were first interviewed is 24 years and females cover about 52 per cent of the sample. Table 1 shows four different possibilities of transitions for the young adults. The number of transitions from parental housing to home ownership is more than from private renting to home ownership even though the latter transition is quite normal and highly intended for young adults. Staying in the same tenure is most likely to have the highest numbers in any tenure transition matrix. However, there are some transitions that are least likely except when they are as a result of chaos or unforeseen circumstances (Ford et al., 2002). Examples of such chaotic transitions are movements out of home ownership, into social renting or back to parental housing as a young individual. These instances may be felt in some of the lower numbers of transitions in table 1. Remaining in home ownership has the highest number as it is also the biggest tenure.

Table 1: Sub-division sample of longitudinal data in use and their transition pattern

\begin{tabular}{llllll}
\hline Origin tenure & (To) HO & (To) PR & (To) SR & (To) $\mathbf{P H}$ & Total \\
\cline { 2 - 6 } HO & 22,341 & 559 & 116 & 598 & 23,614 \\
PR & 1,132 & 4,819 & 404 & 468 & 6,823 \\
SR & 337 & 363 & 6,410 & 276 & 7,386 \\
PH & 1,691 & 1,280 & 605 & 14,661 & 18,237 \\
Total & 25,501 & 7,021 & 7,535 & 16,003 & 56,060 \\
\hline
\end{tabular}

Source: Author's estimation from the BHPS data

Note: $\mathrm{HO}=$ Home ownership; $\mathrm{PR}=$ Private renting; $\mathrm{SR}=$ Social Renting; $\mathrm{PH}=$ Parental housing

From table 1, it can be observed that more individuals appear to make the transition to home ownership from parental housing than from private renting on or before age 34 in the period of the survey. This suggests that among these young adults, about 54 per cent of those who transitioned to home ownership followed the 'early nesters' or 'stay at home to own' housing pathway types suggested in Clapham et al. (2014). The data also includes full-time students who may be renting elsewhere and yet to form separate households. 
The multinomial fixed-effects logistic regression ${ }^{8}$ specification employed in this section is derived from the combination of different probabilities (Pforr, 2014; StataCorp, 2013). Four different response variables are constructed to each predict movements out of private renting, social renting, parental housing or homeownership. For each predictor, individuals possess the risk of making the transition into other three housing tenures or remain in the same tenure. Hence, for each response variable, there are four probabilities, i.e. $Y i j=1, Y i j=2, Y i j$ $=3$ and the reference point $Y i j=0$ denoting remaining in the tenure of origin. Equation (1), for example, denotes the probability of an individual ' $i$ ' moving into a different tenure at a time ' $j$ ' relative to remaining in the tenure of origin, and $\beta$ represents the coefficients of our covariates $X$. The same procedure is also repeated in (2) and (3) in each model.

$$
\begin{aligned}
& \operatorname{Pr}\left(Y_{i j}=1\right)=\frac{\mathrm{e}^{\beta_{1} X_{i j}}}{\sum_{k=1}^{K} e^{\beta_{k} X_{i j}}} \\
& \operatorname{Pr}\left(Y_{i j}=2\right)=\frac{\mathrm{e}^{\beta_{2} X_{i j}}}{\sum_{k=2}^{K} e^{\beta_{k} X_{i j}}} \\
& \operatorname{Pr}\left(Y_{i j}=3\right)=\frac{\mathrm{e}^{\beta_{3} X_{i j}}}{\sum_{k=3}^{K} e^{\beta_{k} X_{i j}}}
\end{aligned}
$$

Summation of outcomes ' $k$ ' obtained in the models is reported in relative risks ratio (and zvalues). The summary statistics of useful variables are as shown in table 2. (A table of owneroccupiers by age groups in the starting wave is shown in Appendix A). The statistics of the dependent variables are also summarised in the top four variables in table 2. Alongside established drivers of tenure transition, the BHPS also contains some indicators of social capital. These are variables relating to an indication of neighbourhood likeness $(l \mathrm{knbrd}$ ); frequency of talking to neighbours (frna); level of activeness in a local organisation (orga); and frequency of physical or telephone contact with father or mother (masee, pasee, matel, patel).

Table 2: Summary statistics for the variables under use ${ }^{9}$

\footnotetext{
${ }^{8}$ The multinomial logistic regression trumps other possible methodologies due to the unordered categories of tenure transitions (Kwak and Clayton-Matthews, 2002). The application of duration analysis in this instance further ensures that young adult's tenure transitions are strictly adhered to. Hence, to cater for right-censoring, tenure transitions (i.e. the response variables) are further defined within the timeframe and before age 35 .

9 The observations cover the 24 years of survey (i.e. from $1991-2014$ inclusive)
} 


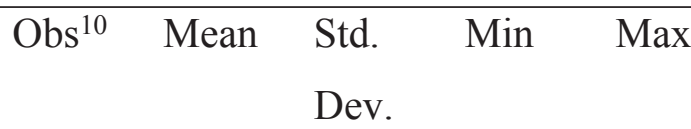

\section{Dependent Variables}

HO transition $d v$

PR transition $d v$

SR transition $d v$

PH transition $d v$

\begin{tabular}{lllll}
\hline 65654 & 0.044 & 0.302 & 0 & 3 \\
65654 & 0.026 & 0.239 & 0 & 3 \\
65654 & 0.067 & 0.365 & 0 & 3 \\
65654 & 0.036 & 0.299 & 0 & 3
\end{tabular}

\section{Established drivers}

Wage rate ${ }_{t-1}$

Working full time ${ }_{t-1}$

Part time work $t-1$

$\begin{array}{lllll}56316 & 0.698 & 1.425 & 0 & 66.75\end{array}$

Unemployed $_{t-1}$

$\begin{array}{lllll}53667 & 0.610 & 0.488 & 0 & 1\end{array}$

Job loss

$\begin{array}{llll}65654 & 0.150 & 0.357 & 0\end{array}$

Female, ref $=$ male

$\begin{array}{llll}65654 & 0.258 & 0.438 & 0\end{array}$

$\begin{array}{lllll}65654 & 0.050 & 0.217 & 0 & 1\end{array}$

Age 25-29 ${ }_{t-1}$, ref= age less than 25

65654

0.530

0.4990

$\begin{array}{lllll}53667 & 0.326 & 0.469 & 0 & 1\end{array}$

Age 30-34 $t-1$

$\begin{array}{lllll}53667 & 0.291 & 0.454 & 0 & 1\end{array}$

No child in household $t-1$

$\begin{array}{lllll}53667 & 0.560 & 0.496 & 0 & 1\end{array}$

Children 1-2 $t-1$

$\begin{array}{lllll}53667 & 0.370 & 0.483 & 0 & 1\end{array}$

Children 3-4 ${ }_{t-1}$

$\begin{array}{lllll}53667 & 0.067 & 0.249 & 0 & 1\end{array}$

Children 5 plus ${ }_{t-1}$

$\begin{array}{lllll}53667 & 0.004 & 0.061 & 0 & 1\end{array}$

Non-white, ref=white

$\begin{array}{lllll}65654 & 0.307 & 0.461 & 0 & 1\end{array}$

Presence of spouse ${ }^{11}$

Joined partner

$\begin{array}{lllll}65654 & 0.516 & 0.500 & 0 & 1\end{array}$

Break-up with partner

$\begin{array}{lllll}65654 & 0.041 & 0.199 & 0 & 1 \\ 65654 & 0.008 & 0.091 & 0 & 1\end{array}$

Quintile 2 house prices $_{t-1}$, ref=quintile 1

$\begin{array}{lllll}53667 & 0.271 & 0.445 & 0 & 1 \\ 53667 & 0.226 & 0.418 & 0 & 1 \\ 53667 & 0.211 & 0.408 & 0 & 1 \\ 56325 & 0.790 & 2.266 & 0 & 49.04\end{array}$

Quintile 3 house prices $t-1$

Quintile 4 house prices $t-1$

Net rent $£ 000_{t-1}$ (lagged)

$56325 \quad 0.790 \quad 2.266$

\footnotetext{
${ }^{10}$ There could be variations in the number of observations obtained from respondents, depending on the variable.

${ }^{11}$ The "presence of partnership in the household" is better replaced with "shock" predictors such as "joining or breaking up with a partner" in some transitions that may look 'chaotic', such as home ownership loss (Ermisch and Di Salvo, 1996). It differs from "joined partner" which refers to partnership formation prior to transition.
} 


\section{Path-dependency drivers}

\begin{tabular}{|c|c|c|c|c|}
\hline 5-9 $\mathrm{YPH}^{12}, \mathrm{ref}=<5$ & 65654 & 0.008 & 0.088 & 0 \\
\hline$>9 \mathrm{YPH}$ & 65654 & 0.011 & 0.104 & 0 \\
\hline \multicolumn{5}{|l|}{ Social capital drivers } \\
\hline Likes neighbourhood $t-1$ & 53667 & 0.879 & 0.326 & 0 \\
\hline $\begin{array}{l}\text { Talks to neighbours more often }{ }_{t-1} \text {, ref=less } \\
\text { often or never }\end{array}$ & 50920 & 0.168 & 0.374 & 0 \\
\hline Moderately talks to neighbours ${ }_{t-1}$ & 50920 & 0.154 & 0.361 & 0 \\
\hline Active in any organisation ${ }_{t-1}$, ref $=$ not active & 53667 & 0.379 & 0.485 & 0 \\
\hline $\begin{array}{l}\text { Contact parent(s) several times a year }{ }_{t-1}, \text { ref }= \\
\text { once a week or more }\end{array}$ & 53667 & 0.217 & 0.412 & 0 \\
\hline Less often contact with parent $t_{t-1}$ & 53667 & 0.566 & 0.496 & 0 \\
\hline
\end{tabular}

Note: $\mathrm{dv}=$ Dependent variable; $t-1=$ lagged by a year; $\mathrm{HO}=$ Home ownership; $\mathrm{PR}=$ Private renting; SR = Social Renting; $\mathrm{PH}=$ Parental housing; $\mathrm{YPH}=$ Years in parental home ownership.

\section{Empirical results}

The multinomial fixed-effects logistic regression results are reported in odds ratio and $\mathrm{z}$ values over 12 models. All models include the year dummies but they are not reported for brevity. Results from the path-dependency and social capital drivers are displayed in table 3 while appendix 1 displays the results from the established drivers. Table 3 and appendix 1 display results from tenure transitions from Private Renting (PR), Social Renting (SR), Parental Housing (PH) and Home Ownership (HO) in that order. The significance level for all interactions is set below 5 per cent except where otherwise stated. The models take on an inventive approach by tracing up original BHPS individuals into the UKHLS. Furthermore, the models describe the effect of a unit change in one variable on the risk of making the transition, relative to the risk (odds) of remaining in the same tenure. From the likelihood ratio (LR) test, all models show statistical significance.

Another possible interpretation of results after logistic regression is to obtain the marginal effects or marginal changes in the independent variables (Cameron and Trivedi 2009). However, there is a need to control for unobserved heterogeneity in causal relationships as is

\footnotetext{
${ }^{12}$ From the BHPS, the number of years of home ownership for a household is calculated and matched with household individual's age at the year of survey and prior to becoming independent or changing household.
} 
the case in this study. As fixed-effects regression is instrumental for controlling for unobserved heterogeneity, Pforr (2014) suggests that the interpretation of the odds ratio is the only realistic choice for multinomial fixed-effects logistic regression.

\section{Established drivers of housing tenure transition ${ }^{13}$}

Labour market conditions are very important predictors of tenure shifts. For instance, respondents are highly likely to switch from parental housing to other tenures by a factor of 1.5 odds (i.e. about 50 percent) when their wage rate increases by a unit. The suggests that young individuals are eager to leave their parental homes to form separate households and this tended to also relate to their ability to afford whichever tenure they could move to. The result also demonstrates the tendency of some individuals to stay at home until they can afford their own place. This may explain the results from the young adults' higher possibilities of remaining in the same tenure, rather than making the transition from private renting to home ownership, following a unit increase in wage rate. However, wage rate has no significant effect on the risk of switching from social renting to other tenures, relative to remaining in the same tenure. This suggests that switching from social renting to another tenure might be affected by factors other than the wage rate.

Another labour market condition which might affect housing tenure decisions is the type of employment. Full-time workers are more likely to make the transition to home ownership than part-time or unemployed workers. Furthermore, young adults are more likely to move from parental housing to renting if they are unemployed. It is believed that independence is paramount and such individuals on low income are likely to depend on housing benefits if they are also renting at the same time (See Kemp, 2000).

Individuals renting privately are more likely to continue renting if they are not working fulltime. They may find it hard returning to parental housing due to embarrassment (Clapham et al., 2014). However, job loss poses the risk of returning to parental housing from home ownership by 6.1 odds. It, therefore, shows that young people represented in the study have the tendency of either staying longer in their parents' house until they can secure home ownership or leave earlier for rented tenures. The suggestion is that they could obtain assistance into any of the rented tenures more easily than home ownership as they seek independence, whereas those who believe they deserve home ownership may remain in their

\footnotetext{
${ }^{13}$ Results are displayed in Table A1 of Appendix A
} 
parental housing for a longer period of time. With the loss of job, however, the situation becomes a dire one as individuals affected may have to return to their parental housing.

For demographic variables, age groups are important. In comparison to individuals aged 24 and below, older parental housing stayers are, generally, more likely to transition to social renting and less likely to transition to private renting. This implies the same notion that individuals would rather stay longer in parental housing to achieve home ownership status. On the contrary, older home owners have higher risk of transition to private renting or parental housing. Also, older private renters have higher risk of switching to home ownership or social renting and lower risk of returning to their parents. In terms of age group and tenure, PRS is often regarded as transition tenure (See Kemp, 2002).

The number of children in the household also shows interesting interactions with tenure transitions. Having no child in the household is the reference point. With an increasing number of children, it is more likely for respondents to move from social renting to home ownership. The odds of transition from PRS to PH reduce by about 0.3 points, provided individuals have 1-2 children in their household. Living in parental housing, with 1-2 children, results in lower risk of leaving the tenure. The suggestion is that more children in household could incur more financial responsibilities which could consequently limit the chances of independent living.

Non-whites appear to have equal chances as whites to make transition. The presence of partnership in the household is an important demographic predictor in tenure transition models. This could also be replaced by shock predictors such as 'joining or breaking up with a partner' in some transitions that may look 'chaotic'. From the results, the presence of a spouse in the household is generally more likely to influence a transition to home ownership, but less likely for parental housing transition. More specifically, joining a partner reduces the risk of transition from home ownership to parental housing. On the other hand, splitting from a partner shows high odds of transition from home ownership to any other tenure. This is considered a chaotic situation whereby affected individual would need to move to any available tenure other than home ownership.

Local Authority District house prices are converted into four quintiles, with the lowest quintile (or least level of house prices) as a reference point. Respondents are most equally likely to switch tenure regardless of levels of house prices in their locality. The suggestion is that those faced with increasing house prices despite being in home ownership are likely 
going to maintain their tenure status despite a possible increase in mortgage rates. Parental housing stayers faced with higher levels of house prices in their locality are more likely than others living with parents to switch to private renting. Affordability concerns in this sense would mean trading off lack of independence (i.e. staying longer in $\mathrm{PH}$ ) with private renting (i.e. independence). When it comes to renting, a unit increase in rent per thousand means that an individual in parental housing is more likely to continue in parental housing than switch tenure. However, with a unit increase in rent per thousand, respondents renting privately are more likely to switch tenure than remain in the rented sector. The implication is that unaffordable rents will either delay independence or force a move out of private renting.

\section{Path-dependency and social capital drivers of housing tenure transition ${ }^{14}$}

The number of years an individual lived in a parental home ownership (YPH) is an important variable that describes path-dependency. It tracks respondents whose parents were home owners and the number of years they lived in parental housing. These individuals may decide to stay in parental housing until they are able to afford their own home or pass through private renting. Home ownership or parental housing is particularly important to individuals who have spent a certain number of years growing up in parental home ownership. This study considers the measure to be more educative than having lived in the same tenure as their parents at some points in the past, as shown in some recent literature. Having lived for four years or less in parental home ownership is coded as the reference point in all the models. Both private renters and home owners with more YPH are more likely than others to return to parental housing. All other respondents are equally likely as others to make transitions from their origin tenure despite having more parental home ownership experience. This suggests that parental housing remains a last resort in difficult circumstances for young people who had significant parental home ownership experience.

\footnotetext{
${ }^{14}$ Results are displayed in table 3
} 
Table 3: Results from Path-dependency and social capital drivers

\begin{tabular}{|c|c|c|c|c|c|c|c|c|}
\hline \multirow[t]{3}{*}{$\begin{array}{l}\text { Path-dependency and social capital } \\
\text { variables }\end{array}$} & $\begin{array}{l}\text { odds } \\
\text { ratio }\end{array}$ & z-value & $\begin{array}{l}\text { odds } \\
\text { ratio }\end{array}$ & z-value & $\begin{array}{l}\text { odds } \\
\text { ratio }\end{array}$ & z-value & & \\
\hline & \multicolumn{6}{|c|}{ Transitions from PR } & & \\
\hline & To HO & & \multicolumn{2}{|c|}{ To SR } & \multicolumn{2}{|l|}{ To PH } & & \\
\hline 5-9 YPH, ref $=<5$ & 1.4885 & 0.70 & 0.0000 & 0.00 & 3.2617 & 1.40 & $N$ (Observations) & $17889^{15}$ \\
\hline$>9 \mathrm{YPH}$ & 1.9162 & 1.19 & 0.0000 & 0.00 & 5.4244 & $3.29 * * *$ & Model wald chi ${ }^{2}$ & $\operatorname{chi}^{2}(138)=2450.05$ \\
\hline Likes neighbourhood & 0.5126 & $-4.47 * * *$ & 0.7654 & -1.59 & 0.8233 & -0.93 & Log likelihood & -2703.44 \\
\hline $\begin{array}{l}\text { Talks to neighbours more often, } \\
\text { ref=less often or never }\end{array}$ & 0.8421 & -1.19 & 0.8372 & -0.90 & 0.7952 & -1.23 & & \\
\hline Moderately talks to neighbours & 0.9326 & -0.43 & 1.3063 & 1.08 & 0.6056 & $-2.18 * *$ & & \\
\hline $\begin{array}{l}\text { Active in any organisation, ref }=\text { not } \\
\text { active }\end{array}$ & 0.9670 & -0.30 & 0.9010 & -0.61 & 0.9570 & -0.28 & & \\
\hline $\begin{array}{l}\text { Contact parent(s) several times a year, } \\
\text { ref= once a week or more }\end{array}$ & 0.6934 & $-2.03 * *$ & 0.9533 & -0.19 & 0.9599 & -0.15 & & \\
\hline \multirow[t]{3}{*}{ Less often contact with parent } & 0.4131 & $-5.30 * * *$ & 0.8072 & -0.99 & 0.8741 & -0.55 & & \\
\hline & \multicolumn{6}{|c|}{ Transitions from SR } & & \\
\hline & To HO & & To PR & & To PH & & & \\
\hline $5-9 \mathrm{YPH}, \mathrm{ref}=<5$ & 2.2707 & 0.96 & 0.0000 & 0.00 & 3.6672 & 1.42 & $N$ (Observations) & 8317 \\
\hline$>9 \mathrm{YPH}$ & 0.0000 & 0.00 & 0.0000 & 0.00 & 6.7028 & $1.69 *$ & Model wald chi ${ }^{2}$ & $\operatorname{chi}^{2}(138)=620.51$ \\
\hline Likes neighbourhood & 0.3666 & $-5.11 * * *$ & 0.4876 & $-4.32 * * *$ & 0.8994 & -0.49 & Log likelihood & -1536.96 \\
\hline $\begin{array}{l}\text { Talks to neighbours more often, } \\
\text { ref=less often or never }\end{array}$ & 1.5248 & 1.56 & 0.8814 & -0.63 & 0.8148 & -0.84 & & \\
\hline Moderately talks to neighbours & 1.9208 & $2.05 * *$ & 0.7683 & -0.99 & 0.6727 & -1.17 & & \\
\hline $\begin{array}{l}\text { Active in any organisation, ref }=\text { not } \\
\text { active }\end{array}$ & 1.2946 & 1.39 & 0.8536 & -0.87 & 0.5128 & $-2.86 * * *$ & & \\
\hline Contact parent(s) several times a year, & 1.3435 & 0.99 & 1.1682 & 0.61 & 0.9939 & -0.02 & & \\
\hline
\end{tabular}

15 The preference for fixed-effects regression leads to a trade-off in number of observations, especially when there are variables with no "within group" variations e.g. sex (Williams, 2015) 


\begin{tabular}{|c|c|c|c|c|c|c|c|c|}
\hline \multicolumn{9}{|l|}{ ref $=$ once a week or more } \\
\hline Less often contact with parent & 0.8097 & -0.97 & 1.0614 & 0.27 & 1.3276 & 1.09 & & \\
\hline \multicolumn{9}{|c|}{ Transitions from PH } \\
\hline & To HO & & To PR & & To SR & & & \\
\hline 5-9 YPH, ref $=<5$ & 0.8509 & -0.39 & 0.0000 & 0.00 & 0.0000 & 0.00 & $N$ (Observations) & 25231 \\
\hline$>9 \mathrm{YPH}$ & 0.4489 & -1.43 & 0.0000 & 0.00 & 0.0000 & 0.00 & Model wald chi ${ }^{2}$ & $\operatorname{chi}^{2}(132)=2507.62$ \\
\hline Likes neighbourhood & 0.8050 & -1.58 & 0.7480 & $-2.24 * *$ & 1.3917 & $2.08 * *$ & Log likelihood & -4353.76 \\
\hline $\begin{array}{l}\text { Talks to neighbours more often, } \\
\text { ref=less often or never }\end{array}$ & 0.7750 & $-1.96 *$ & 0.6970 & $-3.11 * * *$ & 0.8623 & -0.81 & & \\
\hline Moderately talks to neighbours & 1.0517 & 0.35 & 0.7031 & $-2.60 * * *$ & 1.1504 & 0.58 & & \\
\hline $\begin{array}{l}\text { Active in any organisation, ref }=\text { not } \\
\text { active }\end{array}$ & 1.2003 & $2.02 * *$ & 1.0516 & 0.50 & 1.0686 & 0.41 & & \\
\hline $\begin{array}{l}\text { Contact parent(s) several times a year, } \\
\text { ref }=\text { once a week or more }\end{array}$ & n.a. & n.a. & & n.a. & n.a. & n.a. & & \\
\hline \multirow[t]{3}{*}{ Less often contact with parent } & n.a. & n.a. & n.a. & n.a. & n.a. & n.a. & & \\
\hline & \multicolumn{6}{|c|}{ Transitions from $\mathrm{HO}$} & & \\
\hline & To PR & & To SR & & To PH & & & \\
\hline 5-9 YPH, ref $=<5$ & 0.0000 & 0.00 & 0.0000 & 0.00 & 6.8385 & $3.31 * * *$ & $N$ (Observations) & 12114 \\
\hline$>9 \mathrm{YPH}$ & 0.0000 & 0.00 & 1.8420 & 0.45 & 2.4597 & $2.47 * *$ & Model wald chi ${ }^{2}$ & $\operatorname{chi}^{2}(135)=890.78$ \\
\hline Likes neighbourhood & 0.8857 & -0.65 & 1.4618 & 1.03 & 0.9790 & -0.10 & Log likelihood & -2165.77 \\
\hline $\begin{array}{l}\text { Talks to neighbours more often, } \\
\text { ref=less often or never }\end{array}$ & 0.7807 & -1.42 & 0.7241 & -0.81 & 0.9554 & -0.25 & & \\
\hline Moderately talks to neighbours & 1.1244 & 0.59 & 1.0033 & 0.01 & 1.4314 & $1.71^{*}$ & & \\
\hline $\begin{array}{l}\text { Active in any organisation, ref }=\text { not } \\
\text { active }\end{array}$ & 1.1047 & 0.78 & 1.1583 & 0.48 & 0.9668 & -0.24 & & \\
\hline $\begin{array}{l}\text { Contact parent(s) several times a year, } \\
\text { ref= once a week or more }\end{array}$ & 0.6578 & $-2.11 * *$ & 3.3817 & $2.54 * * *$ & 0.8135 & -0.90 & & \\
\hline Less often contact with parent & 0.7990 & -1.22 & 1.4020 & 0.86 & 1.0334 & 0.18 & & \\
\hline
\end{tabular}

Note: $H O=$ Home ownership; $P R=$ Private renting; SR = Social Renting; $P H=$ Parental housing; YPH = Years in parental home ownership. *** denotes significance at $1 \%$; $*$ at $5 \%$; and $*$ at $10 \%$; the predictors are lagged by a year 
Measures reflecting neighbourhood integration and intimacy with parents are treated as social capital drivers. Private renters who indicated their likeness for their neighbourhoods possess a lower risk of entering homeownership than those who do not like their neighbourhood. Both parties to neighbourhood likeness are equally likely to return to their parents. Likewise, social renters are more likely to continue in the same tenure than switch to home ownership or private renting if they liked their neighbourhoods. However, home owning respondents who liked their neighbourhoods are equally likely as other home owners to leave or continue in the same tenure. It would be expected that if a home owner liked the neighbourhood, there may be lower chances of leaving the same neighbourhood rather than the tenure. This suggests that other reasons could better explain movements out of the home ownership tenure, rather than neighbourhood likeness.

Frequency of exchange with neighbours is another important factor that could explain individuals' integration/acceptance in an area. 'Talking to neighbours less often' is made the reference point. Parental housing stayers appear to be most affected by this variable compared to other groups, as they are less likely to make transition to private renting if they socialise more often with their neighbours. There is a possibility of feeling well integrated with neighbours, thereby supressing their motivation to rent privately. This could consequently enable them to wait longer in parental housing until they can afford ownership.

Being active in an organisation could give rise to interactions and relationships formed with trusted individuals, thereby influencing important decisions. Social renters who are active in one form of organisation are less likely to return to their parents than other social renters. Also, parental housing stayers who are active in an organisation are more likely than other PH stayers to move to home ownership. The organisation activeness is not a significant factor in all other transitions. However, element of trust is likely at play, whereby individuals are likely to be influenced into important decision-making due to their interactions with others in social groups.

The last social capital variable considered is the regularity of contact with parents which, in this case, is used as a proxy for intimacy with parents. 'Having contact with parents once a week or more' is coded as the reference point and the individuals under this category are deemed the most intimate with their parents. The predictor is however omitted in transitions from parental housing, as it is expected that several individuals who are yet to form their households are likely to be in more contact with their parents than others. Private renters who 
belong to the category of "the most intimate with their parents" have higher risk than other private renters to transition to home ownership. This brings about a possibility of having a better chance of attaining home ownership due to their closeness to meaningful source of assistance. It also suggests that the category of private renters are likely to turn to parents for financial help, as the tenure is often times regarded as a transition tenure (Ford et al., 2002). The results also show that social renters, who are most likely from the same background (Clapham, 2014), have equal relative risks of transition to other tenures regardless of the level of intimacy with parents. Home owners who are not very much in contact with their parents could transition to SR as they are less likely to expect financial assistance from their parents during chaos ${ }^{16}$. This is because parents are often seen to have a significant influence on their children's housing decisions and outcomes.

\section{Concluding discussions}

Understanding the influences of housing tenure transitions specific to young adults provides a platform to understand their housing decisions in the midst of different circumstances. This paper models a 24-year period of data to investigate the influences of tenure transitions of British young adults. Aside from established drivers of tenure; additional variables indicating social capital drivers are included in these models. The results obtained indicate that young adults tend to remain in their parents' house to save enough and increase their chances of getting assisted into home ownership. The private rented sector, on the other hand, continues to have the lowest rate/number of stayers in the same tenure for all age groups represented in the study, thereby retaining its 'transition tenure' nature despite its recent growth.

The results show interpretations unique to the sample. Despite indications of a rise in the numbers and ages of stayers in parental housing, young individuals appear eager to leave parental housing all the same. This is reflected in the transitions from parental housing. Following a move to private renting, however, there is the possibility of these individuals getting stuck in private renting rather than moving to home ownership, despite an increase in their wage rates. Possibilities of transitions to home ownership are also reduced by being unemployed or in part-time work in comparison to working full-time. In reality, it is possible to remain in private renting rather than moving back to parental housing if the individual is

\footnotetext{
${ }^{16}$ Home ownership loss is a chaotic transition (Ermisch and Di Salvo, 1996).
} 
able to claim housing benefit for being out of work or in low income and unable to meet housing costs.

Alongside the established drivers of tenure, the path-dependency and social capital drivers in the models show interesting results. For instance, the path-dependency predictor (i.e. the number of years lived in parental home ownership (YPH)) further provides insight into the extent of social capital influence in housing tenure literature. Only a small proportion of the sample respondents throughout the survey (i.e. 197 individuals) returned to parental housing from another tenure to start their full-time study. It is therefore interesting to discover that despite the small proportion of parental housing returnees in the survey, the possibility of returning to parental housing in the future increases with more years previously spent in their parental home ownership. With additional years of parental home ownership, they are also more likely to remain in parental housing rather than move out. Certainly, having spent different periods of time in parental home ownership appears to reveal differences in strength of home ownership and parental housing return decisions. This is also in connection with their chances of being assisted into home ownership by their home-owning parents in order to continue in that tenure. It is, however, not possible to examine the source of funds for home ownership as the information is not available in the BHPS.

Home owners are generally known to have the highest stability rates compared to other tenure occupants ${ }^{17}$. Movement out of this tenure is usually associated with chaos or unprecedented circumstances. This may further explain why neighbourhood integration measures have no substantial effect on such a transition. However, with lower chances of parental assistance, social rented sector could be a possible destination. This goes to re-affirm the importance of parental intimacy to young people, which could be valuable to them at certain crucial moments. It is believed that parents have a strong influence on their children and are likely to play a big role in their important decision making. Parents are also in a better position of assisting their children into certain tenures, such as home ownership or a return to parental housing. This is further evident in transitions from private renting as they have a lower chance of transitions to home ownership or return to parental housing if they contact their parents less often. No doubt, the disadvantage stemming from lack of parental resource or guidance could continue to worsen social mobility in Britain.

\footnotetext{
17 See table 1.
} 
The strength of neighbourhood integration and how it may delay housing tenure transition for young people is shown in this study. Some studies have argued that young people are staying longer in either private renting or parental housing largely due to economic reasons ${ }^{18}$. However, the neighbourhood social capital drivers tested in this study adds further knowledge to the delay in transitions for young adults in Britain. In such context, improved socio-economic and tenure mix in neighbourhoods could alleviate housing wealth disparity and vice versa. Furthermore, elements of trust in others in the same local networks, representing a "linking" social capital, appear to be effective for young social renters and parental housing stayers' housing tenure decisions. This is because they happen to take advantage of their participation in local organisations, which could expose them to meaningful information and guidance, thereby assisting them in their key housing tenure decisions.

This study aims to assist policymakers in understanding additional drivers of housing tenure decisions from the socio-psychological point of view. The inclusion of additional social capital characteristics into the housing tenure decision model is essential for a deeper understanding of the contribution of socio-psychological behaviour on housing tenure outcomes. Path-dependency in tenure (especially home ownership) may remain strong among young British households over time. This is because the thoughts and actions of individuals oftentimes follow those of close, experienced and trusted people. However, it is not certain whether this is the case with non-home ownership tenures in Britain. The study is unable to investigate individuals with a family history of renting (privately or socially) due to data limitation. However, such individuals may not have the resources for assistance into home ownership in unfavourable conditions, but may be influenced by some social capital indicators such as the surrounding trends, social connections or close individuals during their housing tenure decision-making. Social capital should, therefore, not be overlooked as additional contributors to housing tenure transitions for young British adults.

\footnotetext{
${ }^{18}$ Prominent among the studies are Gatherwood (2011) and Andrew and Meen (2003).
} 


\section{References}

Ab Majid, R., Said, R. and Daud, M. N. 2014. The Assessment of Young Couples' Behaviour on Expenditure Towards Homeownership. Research Journal, 35.

Andrew, M. and Meen, G. 2003. Housing transactions and the changing decisions of young households in Britain: the microeconomic evidence. Real Estate Economics, 31, 117-138.

Andrew, M. 2012. The changing route to owner-occupation: the impact of borrowing constraints on young adult homeownership transitions in Britain in the 1990s. Urban Studies, $49,1659-1678$.

Arundel, R. and Lennartz, C., 2017. Returning to the parental home: Boomerang moves of younger adults and the welfare regime context. Journal of European Social Policy, 27(3), pp.276-294.

Baddeley, M. 2011. Social Influence and Household Decision-Making: A Behavioural Analysis of Housing Demand. CWPE 1120. Faculty of Economics and Gonville and Caius College, University of Cambridge. UK.

Ben-Shahar, D. 2007. Tenure choice in the housing market psychological versus economic factors. Environment and Behavior, 39, 841-858.

Bourassa, S. C. 1995. A model of housing tenure choice in Australia. Journal of Urban Economics, 37, 161-175.

Brady, G., 2015. Network social capital and labour market outcomes: Evidence for Ireland. The Economic and Social Review, 46(2, Summer), pp.163-195.

Brook, K., 2005. Labour market participation: the influence of social capital. Labour Market Trends, 3(1), pp.113-23.

Cameron, A. C. and Trivedi, P. K. 2009. Microeconometrics using stata. Stata press College Station, TX.

Clapham, D. F. 2005. The meaning of housing: A pathways approach. The Policy Press.

Clapham, D., Mackie, P., Orford, S., Thomas, I. and Buckley, K. 2014. The housing pathways of young people in the UK. Environ. Plan. A, 46, 2016-2031. 
Coulter, R. 2016. Parental background and housing outcomes in young adulthood. Housing Studies, 1-23.

Curran, P. J., Obeidat, K. and Losardo, D. 2010. Twelve frequently asked questions about growth curve modelling. Journal of Cognition and Development, 11, 121-136.

Di Salvo, P. and Ermisch, J. 1997. Analysis of the dynamics of housing tenure choice in Britain. Journal of Urban Economics, 42, 1-17.

Drew, R. B. Believing in Homeownership: Behavioral Drivers of Housing Tenure Decisions. Hoint Center for Housing Studies.

Druta, O. and Ronald, R., 2017. Young adults' pathways into homeownership and the negotiation of intra-family support: A home, the ideal gift. Sociology, 51(4), pp.783-799.

Ermisch, J. and Di Salvo, P. 1996. Surprises and housing tenure decisions in Great Britain. Journal of Housing Economics, 5, 247-273.

Ford, J., Rugg, J. and Burrows, R. 2002. Conceptualising the contemporary role of housing in the transition to adult life in England. Urban studies, 39, 2455-2467.

Fu, K. A Review on Housing Tenure Choice. Proceedings of the 17th International Symposium on Advancement of Construction Management and Real Estate, 2014. Springer, $351-360$.

Gathergood, J. 2011. Unemployment risk, house price risk and the transition into home ownership in the United Kingdom. Journal of Housing Economics, 20, 200-209.

Heath, S., 2008. Housing choices and issues for young people in the UK. Joseph Rowntree Foundation, York.

Henderson, J. V. and Ioannides, Y. M. 1983. A model of housing tenure choice. The American Economic Review, 98-113.

Kemp, P.A., 2000. Housing benefit and welfare retrenchment in Britain. Journal of Social Policy, 29(2), pp.263-279.

Kemp, P., 2002. Private renting in transition. (Coventry: Chartered Institute of Housing).

Kwak, C. and Clayton-Matthews, A., 2002. Multinomial logistic regression. Nursing research, 51(6), pp.404-410. 
Łaszek, J. 2013. Housing in consumer's theory, MPRA Paper 52599, University Library

of Munich, Germany.

Lersch, P.M. and Luijkx, R., 2015. Intergenerational transmission of homeownership in Europe: Revisiting the socialisation hypothesis. Social science research, 49, pp.327-342.

Leviten-Reid, C. and Matthew, R.A., 2018. Housing Tenure and Neighbourhood Social Capital. Housing, Theory and Society, 35(3), pp.300-328.

Lin, N., 2017. Building a network theory of social capital. In: Social capital (pp. 3-28). Routledge.

Lux, M., Samec, T., Bartos, V., Sunega, P., Palguta, J., Boumová, I. and Kážmér, L., 2018. Who actually decides? Parental influence on the housing tenure choice of their children. Urban Studies, 55(2), pp.406-426.

Mandell, J., 2010. Picnics, participation and power: Linking community building to social change. Community Development, 41(2), pp.269-282.

Pforr, K., 2014. Femlogit - implementation of the multinomial logit model with fixed effects. Stata Journal, 14(4), pp.847-862.

Quercia, R. G., Mccarthy, G. W. and Wachter, S. M. 2003. The impacts of affordable lending efforts on homeownership rates. Journal of Housing Economics, 12, 29-59.

Reid, C. 2013. To Buy or Not to Buy? Understanding Tenure Preferences and the DecisionMaking Processes of Lower-Income Households. Cambridge, MA: Joint Center for Housing Studies of Harvard University.

Robst, J., Deitz, R. and Mcgoldrick, K. 1999. Income variability, uncertainty and housing tenure choice. Regional Science and Urban Economics, 29, 219-229.

Ronald, R. and Lennartz, C., 2018. Housing careers, intergenerational support and family relations. Housing Studies 33 (2): 147-59.

StataCorp. 2013. 'mlogit - Multinomial (polytomous) logistic regression', in StataCorp. Stata 13 Base Reference Manual. College Station, TX: Stata Press, pp 1655-1670. Retrieved from https://www.stata.com/manuals/r.pdf 
University of Essex. Institute for Social and Economic Research, 2010. British Household Panel Survey: Waves 1-18, 1991-2009, [data collection], UK Data Service, 7th Edition, Accessed 23 August 2018. SN: 5151, http://doi.org/10.5255/UKDA-SN-5151-1

Wagner, K. 2014. Intergenerational Transmission: How Strong Is the Effect of Parental Homeownership? Results of a Survey on Households in Austria. Monetary Policy \& the Economy, 49-64.

Williams, R., 2015. Panel data 4: Fixed effects vs random effects models. University of Notre Dame.

Ziersch, A. and Arthurson, K., 2007. Social capital and housing tenure in an Adelaide neighbourhood. Urban Policy and Research, 25(4), pp.409-431. 